UJBM, Vol 1, No. 1, July - Dec. 2002, pp 61-67

ISSN 0975-3311

https:/ / doi.org/ 10.12725/ ujbm.1.9

\title{
THINK - GREEN MARKETING
}

\author{
Suniti Phadke*
}

\section{ABSTRACT}

This article summarises that Indian organisations have a moral obligation to protect the environment.

\section{Green Marketing - The Rationale}

The global consumer is today increasingly concerned with a host of environmental issues like depletion of ozone layer, acid rain, disappearance of rain forests, greenhouse effect, waste disposal and landfills, air and water pollution and bio-degradability. It is imperative that businesses should modify their behaviour with a view to address these concerns. Besides, there is need for companies to adopt adaptive strategies to comply with environmental legislation.

Some Indian companies have been quick to accept "Green Marketing" or "Environmental Marketing" philosophy. They have integrated environmental issues into all organizational activities and processes. However, there are many who have not taken their responsibility for environmental protection seriously.

\section{What is Green Marketing?}

Over time, the idea of green marketing has undergone change. If the emphasis in the 70 s was on mitigating the negative effects of pollution, the emerging paradigm is that of enhancing the environmental image of companies. Let us consider some of the definitions:

* Associate Professor of Marketing, Christ College Institute of Management 
"Green Marketing is the study of positive and negative aspects of marketing activities on pollution, energy depletion and non energy resource depletion." (Henion and Kinnear-1976)

"Green Marketing is the development and implementation of marketing programmes that are designed to enhance an organisation's environmental image". (Schoell and Guiltinan-1992)

"Green or Environmental Marketing consists of all activities designed to generate and facilitate any exchange intended to satisfy human needs or wants, such that the satisfaction of these needs and wants occur, with minimal detrimental impact on the natural environment." (Polonsky-1994)

\section{The Environmental Market Place}

Today's consumers are environment conscious. Research has shown that about 42 percent of U.S consumers are willing to pay higher prices for "green" products. (Kotler). They are loyal to brands and companies that are perceived as friendly to the environment. Environmental concerns are influencing the buying decisions of more and more consumers and have forced consumers to question their assumptions about the type of products that best meet their needs. Paper no longer needs to be white. Recycled content, once deemed inferior, even unclean, is preferable to virgin. Disposable products, once associated with feelings of satisfaction, now make consumers feel guilty.

\section{Green Marketing Initiatives}

Indian organisations can put into practice Green Marketing initiatives that will cause less harm to the environment. These will facilitate the innovative culture needed to radically change products and processes toward sustainability.

\section{Introduce Environmentalism as a Corporate Philosophy}

Environmental concerns must become an integral part of the business system; the company can set environmental goals, E.g. Dupont has an environmental goal of "zero waste." Wal-Mart's commitment to a cleaner environment influences the choice of products sold in its store.

The organisations can develop a pro environment attitude among their employees, customers, and the general public. E.g., Lost Arrow Corporation keeps a master calendar showing who is travelling where and when and encourages employees to co-ordinate their trips to avoid unnecessary travel. 


\section{Engage in Cause-related Marketing}

Cause-related marketing is the process of formulating and implementing marketing activities that are characterised by an offer from the firm to contribute a specified amount to a designated cause. E.g. Proctor and Gamble offered to donate 10 percent coupon redeemed (up to $\$ 100,000$ ) to "Keep America Beautiful." Companies may also decide to support green organisations like World Wild Life Fund, Green Peace etc.

\section{Develop Green Products}

Green products are typically durable, non-toxic, made from recycled materials, or minimally packaged. There are no completely green products, for they use up energy and resources and create by-products and emissions during their manufacture, distribution, usage and disposal. So, green is relative, describing those products with less impact on the environment than alternatives.

A range of alternatives are available to green marketers.

- Development and marketing of products that do not damage environment. For example, eveready is manufacturing batteries free of mercury, Body Shop cosmetics are made with products that are not tested on animals.

- Develop new products using high technology. For example, Maytag introduced a horizontal axis washing machine (Neptune) which is water and energy efficient.

- Initiate product modification so that they have less impact on the environment. For example, in Germany, homes must be designed so that rain water can be collected from rooftops for landscaping purposes. Xerox introduced a high quality recycled photocopier paper in an attempt to satisfy the demands of firms for less environmentally harmful products.

- Make packaging changes so as to have Bio-degradable packs, wrappers and containers. For example, McDonalds eliminated their polystyrene cartons and now use smaller, paper wrappings.

- Use recyclable material. For example, Heinz is using recycled ketchup bottles. L'eggs pantyhose dropped the plastic egg container for a new recycled-cardboard box.

- Develop complementary products to increase the effectiveness of other new environmentally sustainable products. For example, Procter and Gamble developed Tide HE (high efficiency); a detergent specially 
formulated for compatibility with Maytag's Neptune washing machines which is water and energy efficient.

\section{Encourage Re-consumption}

Reconsumption refers to the making products such that the materials, components and packages can be used longer and re-used either in part or as whole. Forms of reconsumption include - refilling, repairing, restoring and re-using. For example:

\# Refilling-Accutone has designed cartridges so they can be refilled; otherwise they had to be discarded.

\# Repairing-SKF, a Swedish bearing manufacturer, has developed a series of preventive support services and diagnostic techniques that its customers can use greatly to lengthen the life of its bearings.

\# Restoring-BMW and Mercedes is now restoring damaged auto parts that in the past were simply discarded.

\# Re-using-Lego, the Danish toy manufacturer, delivers its products to retailers in large, durable boxes that are returned to Lego for re-use.

5. Change Systems, Not Just Products

- Do not just modify just product features, but overhaul the entire operating system which includes procurement, design, manufacturing, distribution and disposal. IFB ships components to TVS in re-usable pallets. Empty pallets are picked up by trucks on their return journey. Tuna manufacturers modified their fishing techniques because of the increased concern over driftnet fishing, and the resulting death of dolphins.

- Developing new or alternative ways of utilizing limited natural resources while satisfying unlimited consumer wants. For example, Toyota, Nissan and other auto companies are increasing the fuel efficiency of their vehicles.

- Have proper waste management programmes. For example, Walt Disney World has an extensive waste management program and infrastructure in place.

6. Promote or advertise products/services with environmental characteristics

Companies like Body Shop have used their genuine environmental concerns effectively to build a strong brand identity. They promote the fact that they are 
environmentally responsible. The Tourism Industry has successfully innovated and promoted "ecotourism" facilities that help tourists experience nature and at the same time, operate in a fashion that minimizes environmental impact.

\section{Dematerialize, Where Possible}

Dematerialisation involves meeting of consumer needs with fewer materials and resources. For example, Colgate Palmolive designed a new toothpaste tube that eliminated the need for an outer carton by allowing the fube to stand on its own via the use of flat top pad nozzle. Proctor and Gamble has redesigned Crisco plastic bottles to use 28 percent less plastic, compressed Pampers (diapers) into smaller plastic packs, and super concentrated detergent so that they require $15 \%$ less packaging.

\section{Use Demarketing as a Strategy}

Demarketing efforts involve attempts by marketers to reduce demand for goods or services to a level that can be supplied by a firm. Firms like General Electric, Campbell, and Carnation are narrowing their product lines. Exxon, Shell, Texaco, and Gulf have all advertised ways of conserving gasoline. Public utilities now. regularly advertise ways to make homes more energy efficient.

\section{Implement Adaptation Strategies}

A plethora of laws govern environmental issues. A proactive approach needs to be taken in devising strategies to anticipate and adapt fast to changes in the legal environment. Failure of the leather manufacturing industry in Tamil Nadu in India to set up effluent treatment plants led to closure of the units as directed by the Supreme Court.

\section{Re-deploy Resources}

Firms faced with environmental issues in one market can choose to redeploy their resources in other less-exposed areas. ITC has diversified into the hotel industry because of the environmental pressures concerning the health effects of cigarette smoking.

\section{Make Contingency Plans}

Companies can have a de-risking model to counteract the potential environmental effects. For example, a search may be launched for substitutes for raw materials with volatile prices.

Another contingency strategy will involve isolating discrete environmental scenarios the firm may have to face in the future and designing appropriate responses for each. 


\section{Think of Circular Approach}

Learn from Mother Nature. There is no wastage in nature, everything is recycled. The manufactures should shift their thinking from a linear "cradle-to-grave" mode to a more circular "cradle-to-cradle" approach.

Thinking in circles - recycling, re-using, re-manufacturing and compostingwill provide opportunity to save money, create valuable new uses for products and maximise return on assets.

\section{Green Marketing Initiatives - Help Increase Profits}

Green marketing initiatives are not only necessary to maintain competitiveness in many global markets, but also ambitious green goals and environmental leadership can inspire innovation and lead to outright product superiority. The products that can be marketed to main stream consumers on the basis of the health, convenience, good taste, etc. for which consumers buy products in the first place.

Being environmentally responsible is often the same as being efficient. By recycling, cutting down on energy use and conducting environmental audits, companies can reduce operating costs and liability while boosting profits. In addition, creating less waste and using fewer raw materials saves business firms' money. On top of these economic benefits, eco-efficiency enhances employee morale and productivity and creates brand loyalty and improves company reputation.

\section{Conclusion}

Companies must realise that they are members of the wider community and therefore must behave in an environmentally responsible fashion. Environmental issues must get integrated into the firms' corporate culture. Firms marketing goods with environmental characteristics will have a competitive advantage over firms marketing non-environmentally responsible alternatives.

The environmental marketplace will provide a fertile area for organisations. Marketing managers have to think in terms of producing goods and services, packaging goods, and promoting goods that will not permanently damage the natural environment. This type of action-oriented thinking will require much creativity, since the survival of the firm must be matched with the survival of the natural environment. While dealing with environmental issues the marketers should also see that the activities are in compliance with environmental regulation. 
In future, marketers will have to satisfy and delight the environmentally conscious consumers by adopting "Green Marketing" initiatives. Marketers need to build social and ethical considerations into their marketing practices. Indian companies should take a strong pro-environment stance that includes abandoning products/ processes that are environmentally harmful.

Businesses must lead "Green Marketing Revolution" and ensure that they reduce detrimental impact on the environment.

\section{References}

- Kotler Philip, Marketing Management, Prentice- Hall of India Private Ltd, 1999

- Ottman, A. Jacquelyn, Green Marketing: Opportunity for Innovation, NTC Business Books, Second Edition, Lincolnwood, Chicago, 1998.

- J.Ottman Consulting, Inc., 1999-2000, "Developing New Green Business Opportunities".

- Schlesinger M.Jacob, "Japan culfivates an Environmental Image, "The Wall Street Journal, FEB 27,1992.

- Julie Liesse, "Batteries Getting Greener," Advertising Age, Feb 17, 1992.

- Stanton, J.William, Etzel,J.Michael and Walker, J.Bruce, Fundamentals of Marketing, Tata McGraw - Hill, 1994.

- Henion, Karl E., and Thomas C. Kinnear, "A Guide to Ecological Marketing," Columbus Ohio, American Marketing Association, 1976.

- Polonsky, Micheal Jay," A stakeholder theory approach to designing Environmental sound strategies," Greener Management International, 1994.

- "The Greening of Corporate America," Business Week, April 23, 1990.

- Schoell William, Guiltinan Joseph, Marketing, Alyyn and Bacon, 1992.

- Kinnear Thomas, Bernhardt Kenneth; Principles of Marketing, Scott, Foresman / Little, Brown Higher Education, Third Edition, 1990.

- Ellen Neuborne, "Plastic Out,' Green L'eggs the Plan," USA Today, July 10,1991

- Doug Carroll and Desiree French, "Think Green on the Road," USA Today, January $8,1991$.

- Boyd Harper, Walker Orville. Larreche Jean-Claude, Marketing Management, Irwin McGraw-Hill, Third Edition, 1998. 